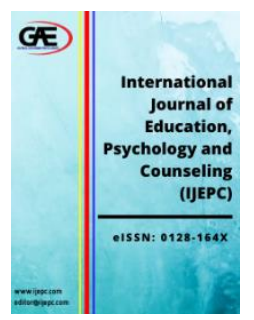

\author{
INTERNATIONAL JOURNAL OF \\ EDUCATION, PSYCHOLOGY \\ AND COUNSELLING \\ (IJEPC) \\ www.ijepc.com
}

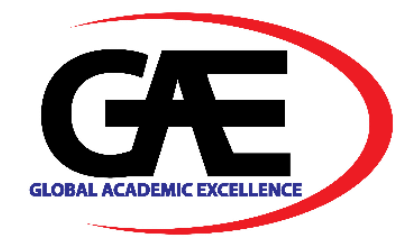

\title{
'THE EFFECTS OF TYPES OF FEEDBACK ON STUDENTS' REVIEWING PROCESS IN AN ONLINE SCAFFOLDED PROCESS WRITING CLASSROOM
}

\author{
Wardatul Akmam Din ${ }^{1}$, Suyansah Swanto ${ }^{2 *}$, Megawati Soekarno ${ }^{3}$, Noraini Said $^{4}$
}

1 Faculty of Psychology and Education, Universiti Malaysia Sabah, Malaysia

Email: wardadin@ums.edu.my

2 Faculty of Psychology and Education, Universiti Malaysia Sabah, Malaysia

Email: suyansah@ums.edu.my

3 Faculty of Psychology and Education, Universiti Malaysia Sabah, Malaysia

Email: megawati.s@ums.edu.my

$4 \quad$ Faculty of Psychology and Education, Universiti Malaysia Sabah, Malaysia

Email: noraini.said@ums.edu.my

* $\quad$ Corresponding Author

\section{Article Info:}

\section{Article history:}

Received date: 11.09 .2021

Revised date: 10.10 .2021

Accepted date: 15.11.2021

Published date: 30.11.2021

\section{To cite this document:}

Din, W. A., Swanto, S., Soekarno, M., \& Said, N. (2021). The Effects of Types of Feedback on Students' Reviewing Process in A Scaffolded Process Writing Classroom. International Journal of Education, Psychology and Counseling, 6 (43), 49-61.

\section{DOI: $10.35631 /$ IJEPC.643005}

This work is licensed under $\underline{\mathrm{CC}}$ BY 4.0

\begin{abstract}
:
There has been growing evidence that the lack of academic writing skills among university students who learn English as a Second Language (ESL) affects their overall academic performance. Higher education ESL students often find writing academic essays a complex process and hence struggle with academic writing convention issues. However, in order to encourage these students' to be autonomous in their English academic writing, explicit and supportive instruction is necessary on the teacher's part. This study aims to investigate thirty Foundation students' revision activities pre- and postintervention and whether there are any changes in their reviewing activities after being exposed to the intervention for twelve weeks. The reviewing activities were categories and analysed for inter-correlations. It is found that the students' revision activities at first seem to concentrate mostly on Surface Changes-Meaning Preserving Changes activities. However, this changes in the second half of the intervention period where they seem to perform more Meaning Changes-Microstructure Changes and the least is Surface ChangesFormal Changes.
\end{abstract}

Keywords:

Process Writing Approach, Scaffolding, Reviewing 


\section{Introduction}

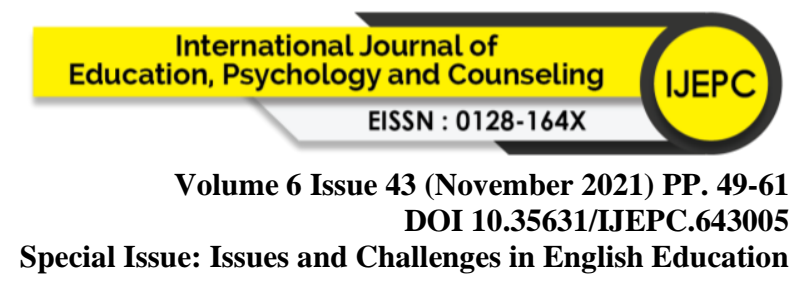

A majority of the research studies on process writing have been done in the west. This study aims to investigate its effects of application in the context of a Malaysian university. The teacher's role in the students' writing processes in this study is to offer comments, encouragement and scaffoldings designed to mould students' writings in definite ways. Classroom activities that consist of pre-writing, drafting, feedback, and revision are undoubtedly fundamental. In fact, it is difficult for the researcher to conceptualise the effective teaching of writing without these activities. However, the students are not forced to follow a prepared route to writing. After being exposed to all the keystones to organized writing, they are given the freedom to compose using their understanding of how the essay should be structured; and consequently, the process is likely to be guided by their own social and cultural views. This intervention expands and broadens the domain of L2 writing with the aim of teaching the students to engage in producing written texts that are closely related to their culture while at the same time produce clear writing (Atkinson, 2003) and not merely teaching the students a decontextualised set of skills or processes that claims to enable them to write.

\section{Literature Review}

Teachers' conceptions of teaching ESL writing are generally guided by their sociocultural background and experiences. The teaching of writing in ESL classrooms can be difficult as writing itself involves complex skills and knowledge construction (Belbase, 2012). Having diverse, multicultural groups of ESL students would make the teaching of writing even more difficult. In most of these circumstances, many teachers resort to teaching merely the correct use of the target language in a writing classroom with little weight given to other aspects of writing, such as content, coherence, and mechanics of writing. According to Hyland (2003:2):

\section{...they [teachers] tend to adopt an eclectic range of methods that represent several perspectives, accommodating their practices to the constraints of their teaching situations and their beliefs about how students learn to write...but it is common for one to predominate in how teachers conceptualize their work and organize what they do in their classrooms...Teachers therefore tend to recognize and draw on a number of approaches but typically show a preference for one of them.}

Although teachers are exposed to alternative approaches to the teaching of writing such as process, product, genre approach, and process genre approach, the widespread tendency in the teaching of writing is to include a focus on grammar (Akinwamide, 2012; Baroudy, 2008; Bruton, 2009, Camps et al., 2019). In the writing instruction, teachers tend to choose any of L2 writing approaches that align with their perspectives and conceptions of teaching writing. It is hoped that this research will provide insights into the complexity of writing as a process, and highlight the composing problems of Malaysian EFL learners in particular.

Hedge (2000: 359) stated that the focus of a process approach "is not so much on what learners need to cover but on how they acquire language through performing it in the classroom". This approach cannot be considered as a teaching method as pedagogical methods are characterised as means that are used in assisting students in their development. The loophole in past researches done in the area of writing processes includes the inability in addressing and clearly 


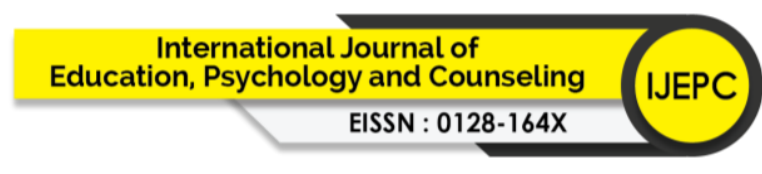

Volume 6 Issue 43 (November 2021) PP. 49-61

DOI 10.35631/IJEPC.643005

Special Issue: Issues and Challenges in English Education implying the pedagogical methods that could help students in embracing more noteworthy processes.

The process approach generally considers writing to be a learner-focused cognitive activity (e.g., composing processes or strategies). Writing is essentially a cognitive activity, completely under the control of the individual learner and used primarily to impart information. Advocates of process pedagogy emphasise that writing is not a product but a process: one that helps students discover their own voice and helps others to recognize that students have something important to say. The process approach involves allowing students to choose their own topics; provides teacher and peer feedback; encourages revision; and uses student writing as the primary text of the course. As time progressed, research on the act of composing began to appear, providing empirical support for the teaching of writing as a process.

Following this developing research, an increasing number of teachers and programmes began to emphasize what Susser (1994) identified as the two essential features of process pedagogy: awareness and intervention. Hairston (1982:122) characterised the move as "a process-centered theory of teaching writing" and thus initiated the thought that the composition studies are probably in the first stages of a paradigm shift. There is no doubt that the process movement helped to call for attention to aspects of writing that had been neglected in many writing classrooms; it also contributed to the professionalisation of composition studies. Examples of practices employing the process pedagogy are writing conferences, the use of student writing as the primary texts of the course, peer review and analytic evaluation tools. This approach removed the focus on writing form and adopted a developmental view of writing, including the use of free writing and peer collaboration (Myers, 1986).

As more teachers began to use this teaching approach, researchers became intrigued by the possible results of a different technique in teaching writing. Interest in the compositions of elementary and secondary students was renewed and this initiated research in the 1980s, using case study approaches and ethnographic research methods. At present, a new line of composition research (Wang, 2004; Wong, 2005; Hu \& Chen, 2007; Weijen et al., 2007; Scott and Palincsar, 2009, Sharhanet al., 2020; Nursazwani et al., 2018; Din et al., 2020) within the classroom context became the focus of research in L2 writing. 


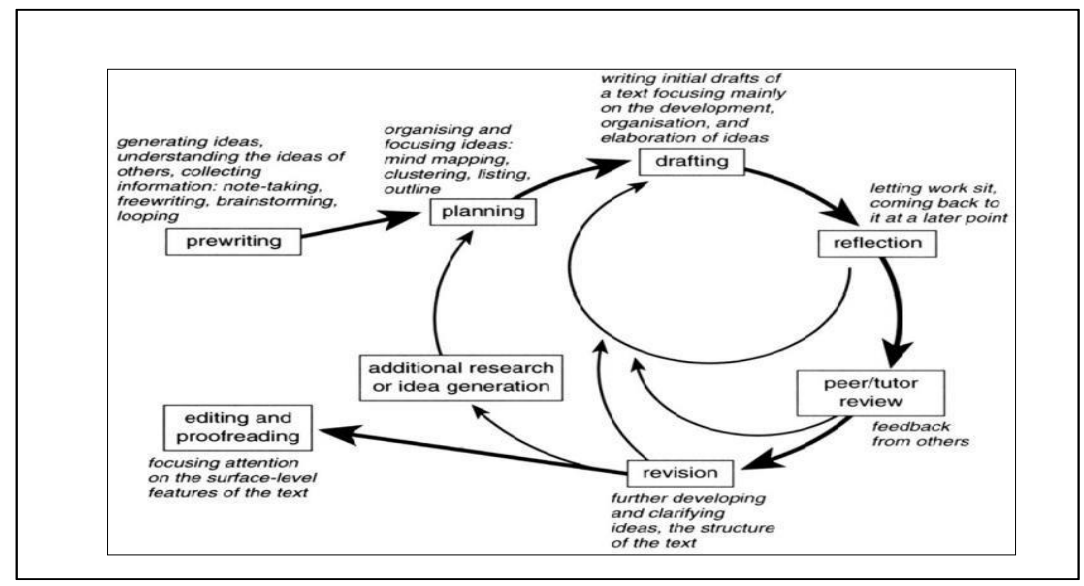

Figure 1: Diagram Of Process Writing. Adapted From Coffin Et Al. (2003).

There are a few specific activities that address reviewing in this approach. During the drafting stage, for example, the writer moves from his/her own thoughts and ideas to producing a text written with the reader in mind. Drafting involves work and rework as multiple drafts are produced following feedback from teachers and/or peers. In the next stage, the students will be reformulating and utilizing all the feedbacks that they have gotten. This stage assists in the development of essential evaluating skills. Checklists can be used to guide feedback. Initially, feedback should be focused on content and organisation. Only when these have been dealt with satisfactorily should comment on language be made.

For the purpose of this research, Faigley and Witte's (1981) Revision Taxonomy was used to analysed all the revision activities done by the students.

\begin{tabular}{|c|c|c|c|}
\hline \multicolumn{2}{|c|}{ Surface Changes } & \multicolumn{2}{|c|}{ Meaning Changes } \\
\hline $\begin{array}{c}\text { Formal } \\
\text { Changes }\end{array}$ & $\begin{array}{c}\text { Meaning } \\
\text { preserving Changes }\end{array}$ & $\begin{array}{l}\text { Microstructure } \\
\text { Changes }\end{array}$ & $\begin{array}{c}\text { Macrostructure } \\
\text { Changes }\end{array}$ \\
\hline $\begin{array}{l}\text { Spelling } \\
\text { Tense, Number, } \\
\text { and Modality } \\
\text { Abbreviation } \\
\text { Punctuation } \\
\text { Format }\end{array}$ & $\begin{array}{l}\text { Additions } \\
\text { Deletions } \\
\text { Substitutions }{ }_{1} \\
\text { Permutations }{ }^{1} \\
\text { Distributions }{ }^{2} \\
\text { Consolidations }\end{array}$ & $\begin{array}{l}\text { Additions } \\
\text { Deletions } \\
\text { Substitutions } \\
\text { Permutations } \\
\text { Distributions } \\
\text { Consolidations }\end{array}$ & $\begin{array}{l}\text { Additions } \\
\text { Deletions } \\
\text { Substitutions } \\
\text { Permutations } \\
\text { Distributions } \\
\text { Consolidations }\end{array}$ \\
\hline
\end{tabular}

Figure 2: Taxonomy of Revisions (Faigley \& Witte, 1981)

\section{Methodology}

This quantitative case study explored the experience and perceptions of thirty-six pre-service ESL teachers enrolled in an undergraduate course who consented to take part in this fourteenweek project.

\section{The Intervention}

Due the Covid19 pandemic, this ESL writing intervention was done entirely in online classes. All students were required to write three drafts essays for two specified topics and, with Copyright $\odot$ GLOBAL ACADEMIC EXCELLENCE (M) SDN BHD - All rights reserved 


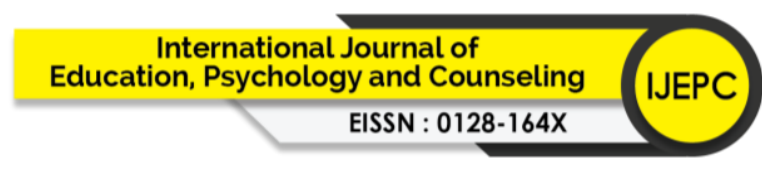

Volume 6 Issue 43 (November 2021) PP. 49-61

DOI 10.35631/IJEPC.643005

Special Issue: Issues and Challenges in English Education training, used the revision checklist provided; revised with peers in pairs, as well as to revise alone.

Thus the intervention was complex, because the procedures were largely new to all of them (writing three drafts, using a checklist and peer revision). The writing revision checklist adapted from two lists in White and McGovern (1994) to reflect learners' errors and their examiners' preoccupations, i.e. low as well as higher levels of writing.

Since the study undertaken was to benefit the participants and deliberately embedded in their normal study, many aspects could not be controlled and no comparable class to serve as a control group was available. Due to the syllabus and exam requirements, the rhetorical types and topics of the writing tasks varied more than would be ideal in a classical study. Two English Associate Professors who have taught different levels of English writing courses at Universiti Malaysia Sabah have reviewed this module. Their comments were acted upon in the reviewed version.

\section{Research Procedure}

The researcher taught 180 minutes of online composition class once every week from 11 am $2 \mathrm{pm}$ for twelve weeks. The participants were 30 Foundation students. Students were made aware that a research project was in progress: for them this new teacher is going to teach them with new ways of teaching.

In the first three weeks the students are exposed to what the researcher calls keystones to good writing. They are:

1. Keystone 1: Thesis Statement

2. Keystone 2: Body Essay

3. Keystone 3:Introduction

4. Keystone 4: Conclusion

This is in response to Din (2012) findings, which recommend that the process writing strategies should be integrated with the formal aspects of writing and must also be an important component in writing instruction.

The researcher then on all composition writing occasions practices led collective planning orally and interactively with notes on MS TEAMS for 30-40 minutes. Emphasis was on generating and evaluating ideas, and discussing organisation (i.e. the higher levels of writing).

The students were exposed to training sessions on the nature of process writing and how to use the strategies. The students were also taught to use the checklist for review by applying it to sample essays. Students had to evaluate a sample essay and discuss problems in class. There was also training on pairwork, which was not common to these students, with practice in revising problems in sample essays under teacher supervision.

In the fourth week, the students started with writing the first of the two essays. In class, learners worked in pairs or groups in breakout rooms as much as possible to share ideas and knowledge.

The first stage of a process approach to writing was generating ideas. An example of the first stage of preparing to write an essay was utilizing a reading text. In pairs they were asked to 


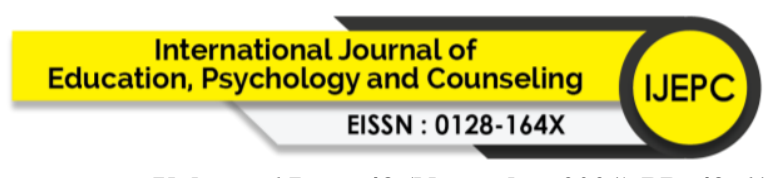

Volume 6 Issue 43 (November 2021) PP. 49-61

DOI 10.35631/IJEPC.643005

Special Issue: Issues and Challenges in English Education extract all the four keystones from the reading text. In the second part, based on the information that they had extracted, they were asked to rewrite the essay in their own words.

In the next class, they were asked to generate ideas without the aid of any texts. They were usually given 3 minutes to work alone, writing one idea on each piece of paper, before comparing in groups. Each group then presented their three best ideas to the class on MS TEAMS. This was to help the learners to start writing.

The next stage taken from a process approach was focusing on the ideas, and it involved thinking about which of the many ideas generated were the most important or relevant, and perhaps taking a particular point of view. As part of the essay-writing process, students in groups put the ideas generated in the previous stage onto a 'mind map'. The teacher then asked the groups to share their mind-maps to the class after they completed it in the breakout rooms. These sharing sessions provided samples of how this particular activity can be done using ideas from the different groups.

Then, the students were asked to write individually their first draft of the essay for about 20 minutes, without stopping and without worrying about grammar or punctuation. If they didn't know a particular word, they wrote it in their L1. This often helped learners to further develop some of the ideas used during this ideas generating stage. Learners then compared together what they had written, and used the online dictionary, the teacher or each other to find in English any words or phrases they wrote in their L1.

Once the students had generated their own ideas, and thought about which were the most important or relevant, the teacher went around the class to give the students the tools to express those ideas in the most appropriate way. For example, during the first class of Essay 1 the teacher employed the examination of model texts, which was often prominent in product or genre approaches to writing. This exercise was to help raise learners' awareness of the conventions of typical texts of different genres in English.

During the first class of Essay 2, the teacher gave the learners in groups several examples of the genre, and they were asked to identify the features and language they had in common. This raised their awareness of the features of the genre and gave them some language 'chunks' they could use in their own writing. They were asked to identify the thesis statement, topic sentences, supporting ideas, etc.

The learners were also given activities of an essay with the topic sentences taken out, and they were asked to put them back in the right place. This raised their awareness of the organisation of the essay and the importance of topic sentences. Once they had seen how the ideas were organised in typical examples of the genre, they went about organising their own ideas in a similar way. In groups in separate breakout rooms, they drafted a plan of their work, including how many paragraphs and the main points of each paragraph. When preparing to write an essay, students grouped some of ideas produced earlier into main and supporting statements.

In a pure process approach class, the writer had to go through several drafts before producing a final version. In practical terms, and as part of a general English course, this was not always possible. Nevertheless, in this online intervention class, the students were asked to write at least 


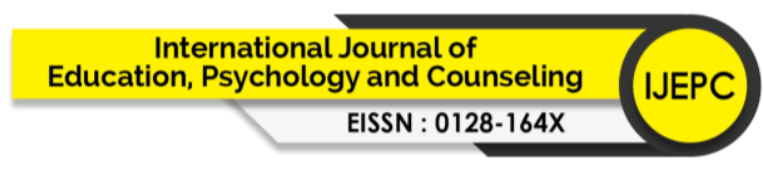

Volume 6 Issue 43 (November 2021) PP. 49-61

DOI 10.35631/IJEPC.643005

Special Issue: Issues and Challenges in English Education three drafts. The writing was done in the online classes, individually or collaboratively in pairs or groups.

Peer evaluation of writing helped learners to become more aware of an audience other than the teacher. The other learners were asked to comment on what they liked or didn't like about the piece of work, or what they found unclear, so that these comments could be incorporated into the second draft. This was also done online using breakout rooms on MS TEAMS. The teacher also responded at this stage by commenting on the content and the organisation of ideas, without yet giving a grade or correcting details of grammar and spelling.

When writing a final draft, the students were encouraged to check the details of grammar and spelling, which took a back seat to ideas and organisation in the previous stages. Instead of correcting the students' writing herself, the teacher used track changes and codes to help students correct their own writing and learn from their mistakes.

By going through some or all of these process writing stages, learners used their own ideas to produce a piece of writing that used the conventions of a genre appropriately. These processes were repeated for both the essays. The students became familiar with the processes as they progressed with the process writing classes.

\section{Data Collection Method and Analysis}

\section{Written Essays}

The researcher investigated the students' progress in writing through the analysis of multiple drafts of their writings. By collecting and analysing these, the researcher hoped to be able to understand their learning development over the semester and also to triangulate the data collected, i.e. to evaluate whether the intervention had the desired effects on students' writing skill. The students were asked to write two types of essays as stated in the Course Synopsis, i.e. Discoursal and comparative. The essays were marked using the UMS marking scheme because they were also constituted as the assessment for the course.

The students' essays comprised both drafts and completed work. In total the students had to complete two types of essays. The first one was collected in week seven and the second in the last week of teaching. All written works were collected, and changes in students' writing skills were analysed, if any, at the different stages of the course.

\section{Data Analyses Procedure of Students' Written Essays}

The data analysis of this study stressed on the process of making sense of the data collected. Bogdan and Biklen (1998) state that data analysis involves the systematic searching and arranging of interview transcripts, field notes and other materials accumulated by researchers. It was useful to increase the understanding of the phenomenon being examined as it required the researcher to organise data into manageable units, synthesising, searching for patterns, and discovering what there was to tell others.

The students' essays comprised both drafts and completed work. In total the students had to complete two types of essays. The first one was collected in week seven and the second in the last week of teaching. All written works were collected, and changes in students' writing skills 


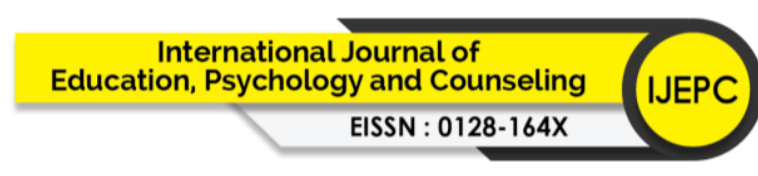

Volume 6 Issue 43 (November 2021) PP. 49-61

DOI 10.35631/IJEPC.643005

Special Issue: Issues and Challenges in English Education were analysed, if any, at the different stages of the course. The essays were analysed to determine whether they concentrate on making Surface and Meaning Changes when reviewing their essays.

Pearson correlation is executed to measure the inter-correlations between constructs with regards to Surface and Meaning Changes made by the student when reviewing their essays. Correlation coefficients can range from the value of -1.00 to +1.00 (Lind, Marchal \& Wathen, 2011). The value of -1.00 represents a perfect negative correlation while a value of +1.00 represents a perfect positive correlation. In this study, two sets of correlations were executed i.e. essay 1 and essay 2.

\section{Findings \& Discussion}

\section{Correlation Analysis among Constructs of Essay 1}

Further assessment of the inter-correlations shows that there is significant association between constructs. Correlations were found among variables, meaning a high degree of linear relationship existed between the variables. First, it is found that there is significant and positive correlation between Surface Changes-Meaning Preserving Changes-Consolidation (SCMPCCon) and two factors: Surface Changes-Meaning Preserving Changes-Permutations (SCMPCPerm) $(\mathrm{r}=0.681, \mathrm{p}<0.01)$ and Surface Changes-Meaning Preserving ChangesAdditions (SCMPCAdd) $(\mathrm{r}=0.441, \mathrm{p}<0.01)$. It can also be seen that there is again positive correlation between Surface Changes-Formal Changes-Punctuation (SCFCPunc) and Surface Changes-Formal Changes-Tense (SCFCTen) $(r=0.512)$ at $\mathrm{p}<0.01$.

Similar observation can also be seen between Surface Changes-Meaning Preserving ChangesAdditions (SCMPCAdd) and Surface Changes-Formal Changes-Punctuation (SCFCPunc) $(\mathrm{r}=0.576)$ at $\mathrm{p}<0.01$.

Another observation is that Surface Changes-Meaning Preserving Changes- Substitutions (SCMPCSub) is also correlated and positively significant at $\mathrm{p}<0.01$ with two factors: ) and Surface Changes-Meaning Preserving Changes-Additions (SCMPCAdd) ( $r=0.478$ ) and Surface Changes-Meaning Preserving Changes- Deletion (SCMPCDel) ( $\mathrm{r}=-0.563)$. Subsequently, there is significant and positive correlation between Surface Changes-Meaning Preserving Changes-Consolidation (SCMPCCon) and Surface Changes-Meaning Preserving Changes- Permutations (SCMPCPerm) $(r=0.681)$ at $\mathrm{p}<0.01$.

Next, significant and positive correlations also exists between Meaning ChangesMicrostructure Changes-Permutations (MCMiCPerm) and two factors: Surface ChangesFormal Changes-Punctuation (SCFCPunc) $(r=0.616)$ and Surface Changes- Formal ChangesTense (SCFCTen) $(\mathrm{r}=0.553)$ at $\mathrm{p}<0.01$.

Further, Meaning Changes- Microstructure Changes- Consolidation (MCMiCCon) is correlated and positively significant at $\mathrm{p}<0.01$ with four factors, i.e. Surface Changes-Meaning Preserving Changes-Abbreviations (SCMPCAbb) ( $\mathrm{r}=0.464)$, Meaning ChangesMicrostructure Changes- Deletion (MCMiCDel) ( $\mathrm{r}=0.464)$, Meaning Changes-Microstructure Changes- Substitutions (MCMiCSub) (r=0.580) and extremely high with Meaning ChangesMicrostructure Changes- Permutations (MCMiCPerm) ( $\mathrm{r}=0.802$ ). 


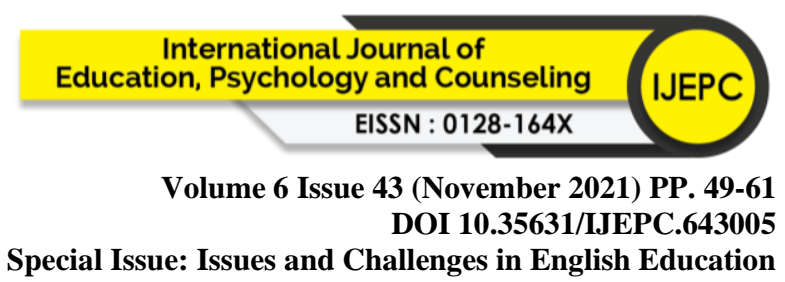

Based on these figures, there is no multicollinearity problem in the research data. Besides, all mean scores are presented on the students' counts of the different revision activities made of which they mainly asserted 2 times of revisions made.

In general, in the first writing activity, after being introduces to the Process Writing Strategies, the students revision activities seem to concentrate mostly on Surface Changes-Meaning Preserving Changes activities as described earlier. This is followed by Meaning ChangesMicrostructure Changes and the least is Surface Changes-Formal Changes.

As explained earlier, Faigley and Witte (1981:402) describe this Surface Changes as "changes that do not bring new information to a text or remove old information". Formal Changes refer to the conventional proof reading activities, meanwhile Meaning Preserving Changes refer to changes that "paraphrase the concepts in the text but do not alter them" (Op.Cit. 403). Meaning Changes, on the other hand, "involve the adding of new content or the deletion of existing content" (ibid.). In other words, the stastistical analysis of the students' first essay reviewing activities indicates that this group of students were still tied to surface changes revision that do not bring in new information. Rather, paraphrasing the original concepts in the text by making them implicit or explicit, without altering the meaning. Thus, they were primarily syntactical or lexical changes.

\section{Correlation Analysis among Constructs of Essay 2}

The findings depict inter-construct correlations of the students' second essay. Results indicate that essay revision activities of these students are inter-correlated with each other, denotation a high degree of linear relationship existed between the constructs. Hence, multicollinearity is absent in this research data. Multicollinearity is an undesirable situation where the correlations among the independent variables are strong. It increases the standard errors of the coefficients. Increased standard errors in turn means that coefficients for some independent variables may be found not to be significantly different from 0 , whereas without multicollinearity and with lower standard errors, these same coefficients might have been found to be significant and the researcher may not have come to null findings in the first place. In other words, multicollinearity misleadingly inflates the standard errors. Thus, it makes some variables statistically insignificant while they should be otherwise significant.

The strongest correlation appears in the association between Meaning Changes- Microstructure Changes-Permutations (MCMiPerm) and Meaning Changes- Microstructure ChangesSubstitutions (MCMiCSub) of which there is a significant positive correlation between them at $\mathrm{p}<0.01$ ( $\mathrm{r}=-0.845)$. This is followed by Meaning Changes-Macrostructure ChangesSubstitutions (MCMaCSub) and Surface Changes- Formal Changes-Abbreviation (SCFCAbb) at $(\mathrm{r}=-0.777, \mathrm{p}<0.01)$.

In third place, Surface Changes-Formal Changes-Punctuation (SCFCPunc) and Surface Changes-Formal Changes-Spelling (SCFCSpl) are also statistically significant ( $\mathrm{r}=-0.759$, $\mathrm{p}<0.01$ ). Fourth, Meaning Changes-Microstructure Changes- Distributions (MCMiDis) and Meaning Changes-Microstructure Changes-Deletions (MCMiCDel) at $(r=-0.557, \mathrm{p}<0.01)$. This is followed by Meaning Changes- Microstructure Changes- Substitutions (MCMiCSub) 


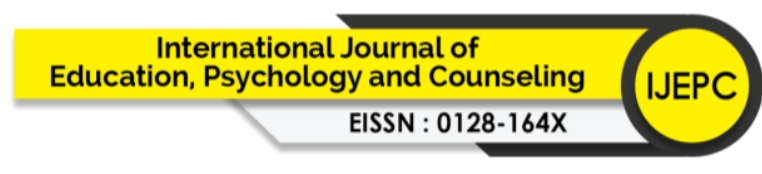

Volume 6 Issue 43 (November 2021) PP. 49-61

DOI 10.35631/IJEPC.643005

Special Issue: Issues and Challenges in English Education and Surface Changes-Meaning Preserving Changes-Distributions (SCMPCDis) at ( $\mathrm{r}=-0.537$, $\mathrm{p}<0.01)$.

Besides these direct correlations, there are also significant and positive correlations that exist between a few factors. The first one is Surface Changes-Meaning Preserving ChangesAdditions (SCMPCAdd) and two factors; Surface Changes- Formal Changes-Spelling $(\mathrm{SCFCSpl})$ at $(\mathrm{r}=-0.532, \mathrm{p}<0.01)$ and Surface Changes- Formal Changes-Punctuations (SCFCPunc) at $(\mathrm{r}=-0.642, \mathrm{p}<0.01)$.

Next, Surface Changes-Meaning Preserving Changes-Deletions (SCMPCDel) and three factors; Surface Changes-Formal Changes-Spelling (SCFCSpl) at $(r=-0.641, p<0.01)$, Surface Changes-Formal Changes-Punctuations (SCFCPunc) at $(\mathrm{r}=-0.752, \mathrm{p}<0.01)$ and Surface Changes-Meaning Preserving Changes-Additions (SCMPCAdd) at $(r=-0.732, \mathrm{p}<0.01)$.

Significant and positive correlations are also found with Surface Changes-Meaning Preserving Changes- Substitutions (SCMPCSub) and three factors; Surface Changes- Formal ChangesPunctuations (SCFCPunc) at $(\mathrm{r}=-0.501, \mathrm{p}<0.01)$, Surface Changes- Meaning Preserving Changes-Additions (SCMPCAdd) at $(\mathrm{r}=-0.829, \mathrm{p}<0.01)$ and Surface Changes-Meaning Preserving Changes-Deletions (SCMPCDel) at $(\mathrm{r}=-0.606, \mathrm{p}<0.01)$.

Finally, Meaning Changes-Microstructure Changes- Consolidations (MCMiCCon) and three factors; Meaning Changes-Microstructure Changes- Additions (MCMiCAdd) at ( $\mathrm{r}=-0.464$, $\mathrm{p}<0.01$ ), Meaning Changes-Microstructure Changes- Substitutions (MCMiCSub) at ( $\mathrm{r}=-0.606$, $\mathrm{p}<0.01)$ and Meaning Changes- Microstructure Changes-Permutations (MCMiCPerm) at $(\mathrm{r}=-$ $0.464, \mathrm{p}<0.01)$ is also present.

The next factor correlates with four other factors, i.e. Surface Changes-Meaning Preserving Changes-Consolidations (SCMPCCon) and Surface Changes-Formal Changes-Spelling $(\mathrm{SCFCSpl})$ at $(\mathrm{r}=-0.517, \mathrm{p}<0.01)$, Surface Changes-Meaning Preserving Changes-Deletions (SCMPCDel) at $(r=-0.424, \mathrm{p}<0.01)$, Surface Changes- Meaning Preserving Changes-Additions (SCMPCAdd) at $(\mathrm{r}=-0.563, \mathrm{p}<0.01)$ and Surface Changes-Meaning Preserving ChangesSubstitutions (SCMPCSub) at $(r=-0.500, \mathrm{p}<0.01)$.

\section{Discussion}

From the analysis of the revision data, it can generally be observed that there is a shift in the students' reviewing activities. They seem to concentrate more on the Meaning ChangesMicrostructure Changes as compared to their reviewing activities with the first essay. Furthermore, with the second essay there is significant evidence of the students doing the Meaning Changes-Microstructure Changes, which was totally absent with the first essay (Meaning Changes-Macrostructure Changes-Substitutions (MCMaCSub) and Surface Changes-Formal Changes-Abbreviation (SCFCAbb) at $(\mathrm{r}=-0.777, \mathrm{p}<0.01)$ ). This is again a statistically significant evidence of improvement in the students' essay writing activities.

In other words, correlations were found among variables when comparing the revision activities at two different times. As mentioned earlier, throughout the intervention, the students were required to write two essays and each was done in three drafts. The revision activities were calculated for all found in the drafts. The revision activities were categorized into two main categories, i.e. Surface Changes and Meaning Changes. During the first essay, from the 


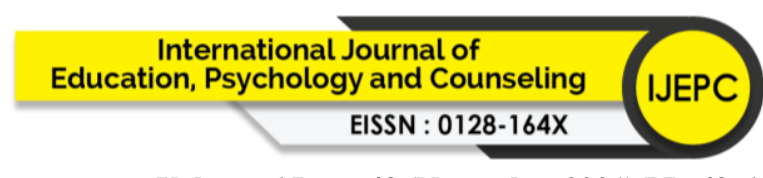

Volume 6 Issue 43 (November 2021) PP. 49-61

DOI 10.35631/IJEPC.643005

Special Issue: Issues and Challenges in English Education data analysis above, it was found that the students produce significant of Surface ChangesMeaning Preserving Changes-Substitutions (SCMPCSub), followed by Surface ChangesMeaning Preserving Changes-Consolidation (SCMPCCon), Surface Changes-Meaning Preserving Changes-Permutations (SCMPCPerm), Surface Changes-Formal ChangesPunctuation (SCFCPunc), Surface Changes-Formal Changes-Tense (SCFCTen), Surface Changes-Meaning Preserving Changes- Deletion (SCMPCDel) and Surface Changes-Meaning Preserving Changes-Additions (SCMPCAdd). However, in Meaning Changes, only Meaning Changes-Microstructure Changes-Permutations (MCMiCPerm) is correlated and positively significant at $\mathrm{p}<0.01$.

When analyzing the second set of essays, the results indicate that essay revision activities of these students seem to produce more Meaning Changes revisions. The most rampant revision activity found is Meaning Changes-Macrostructure Changes- Substitutions (MCMaCSub). Additionally, they tend to also produce Surface Changes-Formal Changes-Abbreviation (SCFCAbb). They also performed significant Surface Changes-Formal Changes-Punctuation (SCFCPunc), Surface Changes- Formal Changes-Spelling (SCFCSpl), Surface ChangesMeaning Preserving Changes-Deletions (SCMPCDel) and Surface Changes-Formal ChangesPunctuation (SCFCPunc). Thus, it can be safely concluded that in the second essay the students no longer stress on the surface changes revision activities. The surface changes are now the byproducts of their attempts in meaning changes revision.

On the other hand, in answering research question 3, the analysis of the Pre- and Post-tests results seems to indicate that the intervention has had better effects on the students' performance when control is compared to the experimental. The analysis of the experimental group's Pre-, Post- and Delayed-post results further reinforced this finding by demonstrating evidence of improvement in the students' writing performance after 14 weeks of exposure to the intervention as compared to their results before the intervention. The delayed postintervention essay results could indicate retention among the experimental students.

\section{Conclusion}

The analysis of the quantitative revision data in this research significantly indicated that there is a shift in the students' reviewing activities. They seem to concentrate more on the Meaning Changes-Microstructure Changes as compared to their reviewing activities, which was totally absent with the first essay. This is again a statistically significant evidence of improvement in the students' essay writing activities.

The revision activities were categorized into two main categories, i.e. Surface Changes and Meaning Changes. During the first essay, from the data analysis, it was found that the students produce significant of Surface Changes.

When analyzing the second set of essays, the results indicate that essay revision activities of these students seem to produce more Meaning Changes revisions. Hence, it can be safely concluded that in the second essay the students no longer stress on the surface changes revision activities. The surface changes are now the byproducts of their attempts in meaning changes revision. 


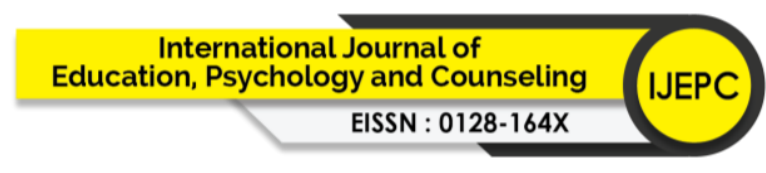

Volume 6 Issue 43 (November 2021) PP. 49-61

DOI 10.35631/IJEPC.643005

Special Issue: Issues and Challenges in English Education

The revision activities were also visible in the qualitative essay analyses. The types of revisions with a decreasing pattern are changes in deletion, singular/plural, pronouns, the verb to be, prepositions, and capitalization, i.e. changes were predominantly at the word, sentence and preserving meaning levels. This could have been due to their proficiency level that handicapped them from revising extensively at the multi- sentential level, for example by adding new text.

When quantified, the data showed that the number of students who did not provide the thesis statement dropped dramatically, especially in the post and delayed post essays. Similar observation was also observed with number of students missing out their topic sentences for the body paragraphs, again especially in the post-intervention and the delayed postintervention essays. Majority of the students also got used to writing paragraph conclusion at the end of their body paragraphs. Last but not least, the students were also seen to produce the bridge in the introduction paragraphs of their essays.

These findings mirror the findings of Keen (2010) and Karlen (2017) who used a certain concept called strategic revision to analyze drafts and revise texts in order to look into strategies and techniques deployed in the process of revision. The findings of Keen's study indicate that some students are aware of a range of goals for writing and are able to use these goals as reference points when redrafting their accounts.

\section{Acknowledgements}

The authors would like to acknowledge Global Academic Excellence (M) Sdn Bhd, who granted the Publication Grant Scheme for this project.

\section{References}

Akinwamide, T.K. (2012). The influence of process approach on English as second language students' performances in essay writing. ELT, 5(3), 16-29.

Atkinson, D. (2003). Writing and culture in the post-process era. Journal of Second Language Writing, 12(1), 49-63.

Baroudy, I. (2008). PROCESS WRITING: SUCCESSFUL AND UNSUCCESSFUL WRITERS; DISCOVERING WRITING BEHAVIOURS. International journal of english studies, Vol, 8, 43-63.

Belbase, S. (2012). Teacher Belief, Knowledge, and Practice: A Trichotomy of Mathematics Teacher Education.

Bruton, A. (2009). The Vocabulary Knowledge Scale: A Critical Analysis. Language Assessment Quarterly, 6, 288-297.http://dx.doi.org/10.1080/15434300902801909.

Camps, Anna \& Fontich, Xavier. (2019). Teachers' concepts on the teaching of grammar in relation to the teaching of writing in Spain: A case study. L1 Educational Studies in Language and Literature. 19, Running Issue. 1-36. 10.17239/L1ESLL-2019.19.02.02.

Coffin, C., Curry, M. J., Goodman, S., Hewings, A., Lillis, T. M., \& Swann, J. (2003). Teaching academic writing: A toolkit for higher education. London: Routledge

Din, W. A. (2013). The effects of a process approach on the writing of tertiary level ESL students in Malaysia. Unpublished MPhil. Dissertation, University of Manchester, UK.

Din, W. A., Saikim, F. H., Swanto, S., Latip, N. A. A., Ismail, I. H., \& Rasit, M. R. A. (2020). Students' Perspectives on The Effectiveness of Problem-Based Learning with Inverted 


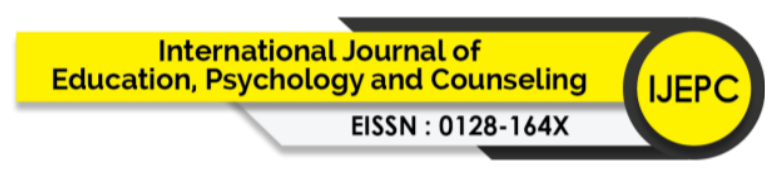

Volume 6 Issue 43 (November 2021) PP. 49-61

DOI 10.35631/IJEPC.643005

Special Issue: Issues and Challenges in English Education Classroom Assistance in Improving Understanding of Foundations Courses (Persepsi Pelajar Terhadap Keberkesanan Pembelajaran Berasaskan Pemasaalahan dengan Bantuan Inverted Classroom untuk Memperbaiki Pemahaman Pelajar dalam KursusKursus Asas). Akademika, 90(2).

Faigley, L. \& Witte, S. (1981). Analyzing revision. College Composition and Communication, 32, 400-414.

Hairston, M. (1982). The winds of change: Thomas Kuhn and the revolution in teaching writing. College Composition and Communication. 33, 76-88.

Hedge, T. (2000). Teaching and learning in the language classroom. Oxford: Oxford University Press.

Hu, G. \& Chen, B. (2007). A protocol-based study of university-level Chinese EFL learners' writing strategies. English Australia Journal, 23(2), 37-55.

Hyland, K. (2003). Second language writing. Cambridge: Cambridge University Press.

Karlen, Yves. (2017). The development of a new instrument to assess metacognitive strategy knowledge about academic writing and its relation to self-regulated writing and writing performance. Journal of Writing Research. 9. 61-86. 10.17239/jowr-2017.09.01.03.

Keen, J. (2010) Strategic revisions in the writing of year 7 students in the UK. The Curriculum Journal, 21(3), 255-280.

Lind, D. A., Marchal, W. G., \& Wathen, S. A. (2011). Statistical techniques in business and Economics. New York, NY: McGraw-Hill Education.

Myers, G.D. (1986). The writing seminar: Broadening peer collaboration in freshmen English. The Writing Instructor, 6(1), 48-56.

Nursazwani, B. D., Dg, Din, W. A., \& AlSaqqaf, A. (2018). Exploring the vaw method of writing among Esl primary pupils: Conceptual paper. International Journal of Applied Linguistics and English Literature, 7(4), 248-252. Available at: https://doi.org/10.7575/aiac.ijalel.v.7n.4p.248.

Sharhan, K., Al-Abedi, H. \& Al-Hilu, M. (2020). Investigating College Students' Problems In Writing English Composition. International Journal of Research in Social Sciences and Humanities. 10. 10.37648/ijrssh.v10i02.010.

Scott, S. \& Palincsar, A.S. (2009). Sociocultural theory. In M. Anderman \& L.H. Anderman (Eds.), Psychology of classroom learning: An encyclopedia. Farmington Hills, MI: Gale Group

Susser, B. (1994). Process approaches in ESL/EFL writing instruction. Journal of Second Language Writing, 3(1), 31-47.

Wang, J. (2004). An investigation of the writing processes of Chinese EFL Learners: Subprocesses, of Chinese learners: Subprocesses, strategies and the role of the mother tongue. Unpublished $\mathrm{PhD}$ thesis, the Chinese University of Hong Kong.

van Weijen, D., van den Bergh, H., Rijlaarsdam, G., \& Sanders, T. (2009). L1 use during L2 writing: An empirical study of a complex phenomenon. Journal of Second Language Writing, 18(4), 235-250. https://doi.org/10.1016/j.jslw.2009.06.003

White, R. \& Mcgovern, D. (1994). Writing: A student's book. English for Academic Study Series. Hemel Hempstead, Hertfordshire: Prentice Hall.

Wong, A. T. Y. (2005). Writers' mental representations of the intended audience and of the rhetorical purpose for writing and the strategies that they employed when they composed. System, 33, 29-47. 